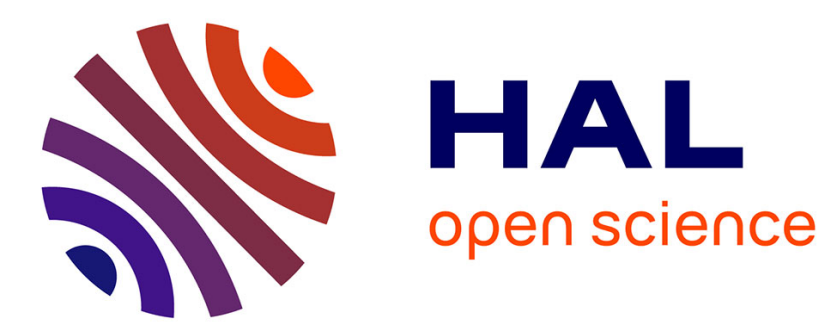

\title{
Measurement of Crassostrea gigas hemocyte oxidative metabolism by flow cytometry and the inhibiting capacity of pathogenic vibrios
}

Christophe Lambert, Philippe Soudant, Gwénaëlle Choquet, Christine Paillard

\section{To cite this version:}

Christophe Lambert, Philippe Soudant, Gwénaëlle Choquet, Christine Paillard. Measurement of Crassostrea gigas hemocyte oxidative metabolism by flow cytometry and the inhibiting capacity of pathogenic vibrios. Fish and Shellfish Immunology, 2003, 15, pp.225-240. hal-00616961

\section{HAL Id: hal-00616961 https://hal.science/hal-00616961}

Submitted on 25 Aug 2011

HAL is a multi-disciplinary open access archive for the deposit and dissemination of scientific research documents, whether they are published or not. The documents may come from teaching and research institutions in France or abroad, or from public or private research centers.
L'archive ouverte pluridisciplinaire HAL, est destinée au dépôt et à la diffusion de documents scientifiques de niveau recherche, publiés ou non, émanant des établissements d'enseignement et de recherche français ou étrangers, des laboratoires publics ou privés. 


\title{
Measurement of Crassostrea gigas hemocyte oxidative metabolism by flow cytometry and the inhibiting capacity of pathogenic vibrios
}

\author{
Christophe Lambert*, Philippe Soudant, Gwénaëlle Choquet, Christine Paillard
}

Laboratoire des Sciences de l'Environnement Marin, Institut Universitaire Européen de la Mer, Université de Bretagne Occidentale, Place Copernic, Technopole Brest-Iroise, 29280 Plouzané, France.

* Corresponding author. Fax: +33-2-98-49-86-55, E-mail address: christophe.lambert@univ-brest.fr (C. Lambert).

\begin{abstract}
A flow cytometric method to measure the production of oxidative metabolism products was adapted for use with Crassostrea gigas hemocytes. The method is based upon the oxidation, by hydrogen peroxide $\left(\mathrm{H}_{2} \mathrm{O}_{2}\right)$, of intracellular 2',7'dichlorofluorescin (DCFH) to green-fluorescent dichlorofluorescein. Activation of the respiratory burst (RB) was tested using phorbol myristate acetate with no success. By contrast, activation by zymosan particles increased oxidation of DCFH in $C$. gigas hemocytes, mainly granulocytes, and optimization tests showed a good response with 20 zymosan particles per hemocyte. Anti-aggregant solution, used to prevent hemocytes from clumping during bleeding, inhibited the RB activity measured by DCFH oxidation. The flow cytometric method developed during this work was used to evaluate the DCFH oxidation-inhibiting capacity of four strains of vibrio bacteria, known or suspected to be pathogenic for bivalves.
\end{abstract}

Keywords: Hemocytes; Oysters; Crassostrea gigas; Flow cytometry; Respiratory burst; 2',7'-Dichlorofluorescin diacetate; Pathogens; Vibrio

\section{Introduction}

Flow cytometry is a routine tool in vertebrate biomedical research. This tool has been applied more recently in marine research. The first description of flow cytometry as a tool to characterize bivalve hemocytes was published in 1977 [1] on work with the giant scallop Placopecten magellanicus, and in bivalve pathology starting in 1988 [2,3]. This powerful tool has often been used, mainly to describe hemocyte population characteristics [4-8] or changes associated with pathology or environmental stress [9-12].

In mammalian biomedical research, flow cytometry has also been developed to monitor the respiratory burst (RB) $\left(\mathrm{H}_{2} \mathrm{O}_{2}\right.$ production) of polymorphonuclear leucocytes [13-16]. Production of reactive oxygen intermediates (ROI's) linked to phagocytosis has been described as an important defense mechanism in bivalves (for a review, see Ref. [17]). ROI production in bivalve hemocytes has been studied by chemiluminescence with luminol [18-20] but to the best of our knowledge, ROI production by Crassostrea gigas during phagocytosis has never been measured using flow cytometry. Thus, the aim of this work was to describe the development of a flow cytometry biotest to measure ROI production $\left(\mathrm{H}_{2} \mathrm{O}_{2}\right)$ in hemocytes of the oyster $C$. gigas and to evaluate the interaction of some pathogenic vibrios with this oxidative metabolism.

\section{Materials and methods}

\subsection{Animals and hemolymph collection}

Adult oysters, $C$. gigas, were supplied by the hatchery of IFREMER (Argenton, France), maintained for 2-15 days in a flow-through seawater system at the laboratory (Institut Universitaire Europe'en de la Mer, Brest, France) at ambient temperature $\left(15-17{ }^{\circ} \mathrm{C}\right)$ and salinity $(33-35 \%$ ) , and processed for hemocyte analysis as follows: hemolymph was withdrawn from the adductor muscle, through a notch previously ground $(24 \mathrm{~h})$ in the oyster shell, using a $1 \mathrm{ml}$ plastic syringe fitted with a 25-gauge needle. Hemolymph from each oyster was transferred into an individual eppendorf tube held on ice. Only individual samples confirmed to be clean of contaminating particles by microscope observation were kept. Hemolymph from at least 18 individuals was pooled; each pool (x3) was composed of hemolymph from six individuals. Pooled hemolymph samples were filtered to $80 \mu \mathrm{m}$ mesh to eliminate aggregates or large pieces of debris. 


\subsection{Chemicals and buffer}

Zymosan stock preparation: $200 \mathrm{mg}$ of zymosan A (Sigma) was suspended in $10 \mathrm{ml}$ of filter-sterilized seawater (FSSW), heated in a boiling-water bath for $30 \mathrm{~min}$, and then washed twice (centrifugation) and resuspended in FSSW. The particle count was checked microscopically using a Malassez cell, and aliquots were frozen at $-20{ }^{\circ} \mathrm{C}$.

Phorbol myristate acetate (PMA, Sigma) stock solution: $1 \mathrm{mg}$ PMA was dissolved in $1 \mathrm{ml}$ dimethyl sulfoxide (DMSO, $99.5 \% \mathrm{~min}$.), divided into aliquots, and stored at $-20{ }^{\circ} \mathrm{C}$.

2',7'-dichlorofluorescin diacetate (DCFH-DA, Sigma) stock solutions: 0.1, 1, 10 and $100 \mathrm{mM} \mathrm{DCFH-}$ DA solutions were prepared in DMSO and then diluted to 10\% in FSSW to produce stock solutions at final concentrations of $0.01,0.1,1$ and $10 \mathrm{mM}$. DMSO was adjusted to $10 \%$ in each stock solution.

Anti-aggregant solution for bivalve hemocytes (AASH) was prepared according to Ref. [21]: $\mathrm{NaCl}$ $2.5 \%$, EDTA $1.5 \%$ in phosphate buffer $100 \mathrm{mM}, \mathrm{pH} 7.4$.

Luminol solution was freshly prepared by 100-fold dilution in FSSW of a stock solution (5-amino-2,3dihydro-1,4-phthalazinedione, $10-1 \mathrm{M}$; in DMSO $1 \mathrm{M}$ ) stored at $-20{ }^{\circ} \mathrm{C}$.

\subsection{Bacteria}

The following cultured bacterial strains were studied:

1. Vibrio tapetis (CECT4600), etiologic agent of the brown ring disease in clams [22-24].

2. Vibrio sp. strain S322, pathogenic for scallop Pecten maximum and oyster C. gigas larvae [25] and known to inhibit chemiluminescent (CL) response of scallop and oyster hemocytes [20,26].

3. V. splendidus II, strain sp7 (named TNEMF6 in Ref. [27]), isolated from juvenile C. gigas during mortality outbreak in France.

4. V. splendidus II, strain 83 , isolated from hemolymph during mortality outbreak in adult oysters $C$. gigas in Argenton hatchery (France).

These strains were cultured in Zobell 2216E medium (Difco) at $18{ }^{\circ} \mathrm{C}$ on a shaker table for $24 \mathrm{~h}$. The bacterial cells were collected by centrifugation $(2500 g, 10 \mathrm{~min})$, washed twice with FSSW, and re-suspended in FSSW. Bacterial-cell density was determined by measurement of optical density (OD) at $492 \mathrm{~nm}$, at which the correlation between direct counts (colony forming unit) and OD had been established previously.

\subsection{Preliminary experiment: $C L$ test}

A preliminary experiment was performed on $C$. gigas hemocytes to evaluate the oxidative metabolism of non-activated and non-anti-aggregant treated cells by chemiluminescence with luminol. Briefly, oysters were bled and pooled (x3) as described previously. After counting, pooled hemolymph samples (three pools) were distributed into plastic scintillation vials (type pico prias vial, 6000192, Packard) at 5x104 cells per vial. This solution was then made up to $2 \mathrm{ml}$ by adding $200 \mu \mathrm{l}$ of the luminol solution and FSSW. Tubes with only luminol and FSSW (x3) were used as controls. Generation of chemiluminescence was measured using a Wallac Guardiane liquid scintillation counter in 'single photon count' mode. Each vial was counted for $30 \mathrm{~s}$ at $t=0,12$, 37, 59, 90, 112, 133 and 155 min. Results of CL activity were expressed in counts per minute (cpm) and presented as instantaneous and cumulative data. 


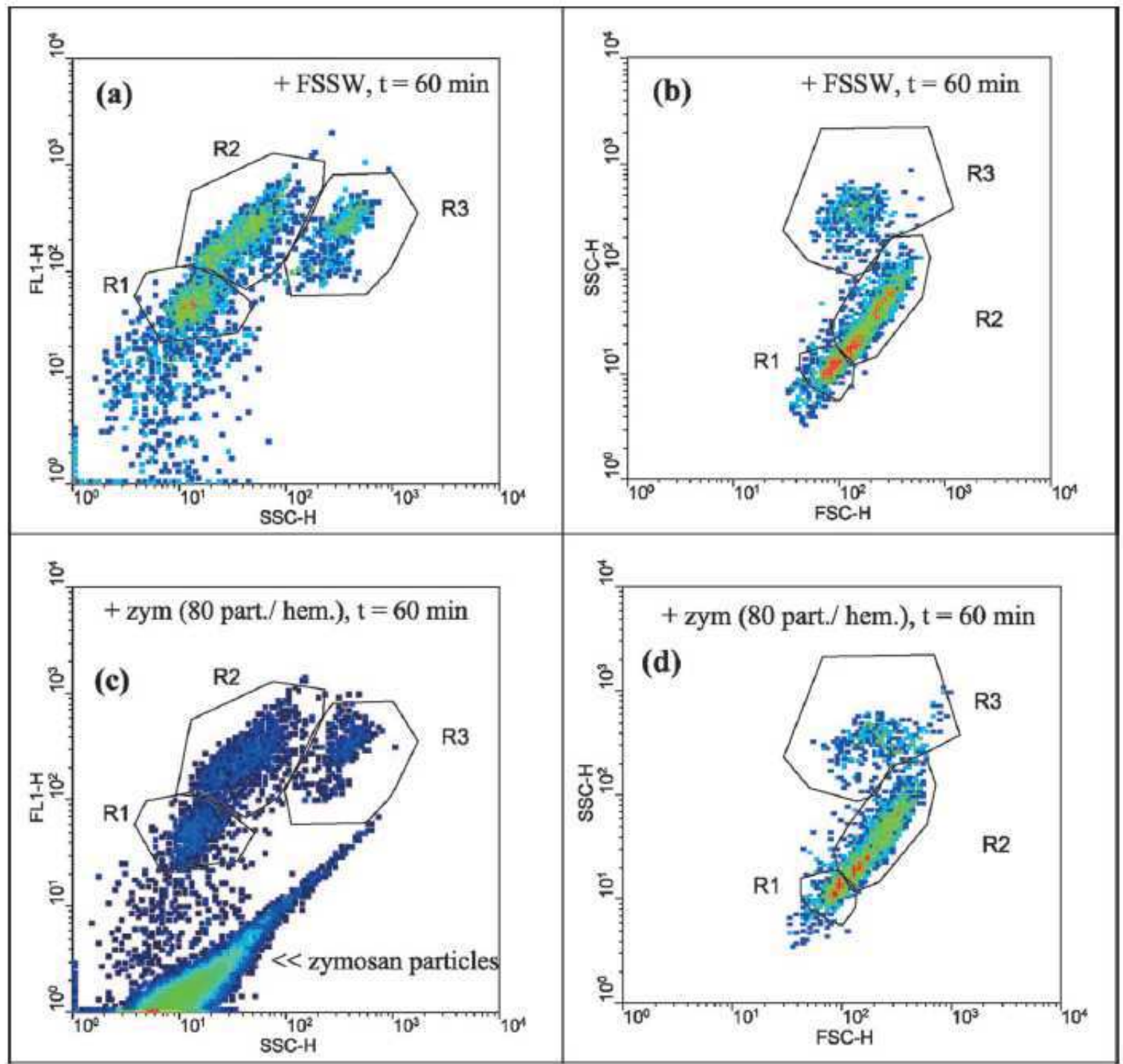

Fig. 1. Typical flow cytometer density plot of $C$. gigas hemocytes, SSC vs. FSC or FL1 vs. SSC (Log scale). Area R1 $=$ small agranular cells, R2=hyalinocytes and R3=granulocytes. (a, b) C. gigas hemocytes sub-populations 60 min after addition of FSSW. (c, d) C. gigas hemocytes sub-populations $60 \mathrm{~min}$ after addition of 80 particles of zymosan per hemocyte.

\subsection{Measurement of RB by flow cytometry: principle}

The method used 2',7'-DCFH-DA and was adapted from Ref. [13]. During incubation with hemocytes, DCFH-DA diffuses into the cells. In the cytoplasm the acetate groups (-DA) are removed by esterase; DCFH is thereby trapped within the cells. The intracellular DCFH, a non-fluorescent fluorescein analog, is oxidized to highly fluorescent dichlorofluorescein (DCF) by hemocytes stimulated to produce ROI by PMA or zymosan. Intracellular DCFH oxidation is quantitatively related to the oxidative metabolism of the hemocyte and mediated by $\mathrm{H}_{2} \mathrm{O}_{2}$. DCF production results in green fluorescence, measurable on the FL1 detector of a flow cytometer.

\subsection{Flow cytometric analysis}

Pooled samples of hemolymph were analyzed on a FACSCalibur flow cytometer (Becton Dickinson, San Diego, CA, USA).

Measurement of hemocyte concentration: $150 \mu \mathrm{l}$ sub-samples, from each of the three pools previously made, were fixed by adding $150 \mu \mathrm{l}$ of a $6 \%$ formalin solution in FSSW and used to evaluate the hemocyte concentration. A microscope count using a Malassez cell was performed in parallel on non-fixed hemolymph. 
Hemocyte sub-populations: hemocytes were divided into three distinct populations corresponding to three cell types - small agranular cells, hyalinocytes and granulocytes; they were separated according to their complexity and oxidative activity using density plot visualization of side scatter (SSC) vs. fluorescent detector (FL1) (Fig. 1a) or according to their size and complexity using density plot visualization of SSC vs. forward scatter (FSC) (Fig. 1b), after gating all active cells showing DCF fluorescence. Sub-populations of hemocytes were still easily recognizable after phagocytosis of zymosan particles as shown by the density plot visualization of SSC vs. FL1 (Fig. 1c) and the density plot visualization of SSC vs. FSC (Fig. 1d), after gating all active cells with DCF fluorescence. It should be noted that zymosan particles showed some auto-fluorescence (Fig. 1c).

Measurements and expression of results: mean level of DCF activity (green fluorescence level in arbitrary unit on the FL1 detector) was evaluated for each hemocyte sub-population at different incubation times by a $30 \mathrm{~s}$ passing of the samples through the flow cytometer. Results are given as mean of fluorescence, in arbitrary FL1 units, for each hemocyte sub-population in the three pooled samples.

\subsection{DCFH-DA dose response}

An initial experiment was performed to define the optimum DCFH-DA dose to be added to hemolymph; this dose should be sufficient to emit a measurable fluorescent signal on the FL1 detector and to be non-toxic for cells. DCFH-DA at $10 \mu \mathrm{M}$ final concentration is commonly used with human neutrophils $[13,14]$. Briefly, oysters were bled, and hemolymph samples were pooled as described previously. Each of the three pools was divided into eight sub-samples of $300 \mu \mathrm{l}$ and distributed into $5 \mathrm{ml}$ polystyrene tubes (Falcon_) maintained on ice. Six microliters of the DCFH-DA stock suspensions $(0.01,0.1,1$ and $10 \mathrm{mM})$ was added to yield final concentrations of $0.1,1,10$ and $100 \mu \mathrm{M}$. After 20 min of pre-incubation with DCFH-DA, $300 \mu$ of zymosan solution at a ratio of 20 particles per hemocyte and $300 \mu \mathrm{l}$ of FSSW for controls, was added to the hemolymph+DCFH-DA solution. Tubes were then incubated at room temperature $\left(20 / 22{ }^{\circ} \mathrm{C}\right)$, and $\mathrm{DCF}$ fluorescence was evaluated just after zymosan or FSSW addition $(t=0)$ and at $t=30,60,90,120$, and $180 \mathrm{~min}$. Results are given as DCF fluorescence in arbitrary units of the different hemocyte populations and for the different DCFH-DA doses and incubation times. Then, a comparison of DCF fluorescence was done for each hemocyte sub-population at different DCFH-DA doses, depending upon whether they were activated or not with zymosan.

\subsection{RB activation assay with PMA or zymosan}

During the adjustment of the DCF assay, two possible RB activating agents were tested: PMA and zymosan. PMA has been used previously to elicit the RB in bivalve hemocytes at a final concentration of $10 \mu \mathrm{g}$ ml-1 [28,29] and was tested at this concentration in the present experiment. A ratio of 80 zymosan particles per hemocyte was established by Bache're et al. [18] as the optimal concentration to activate the $C$. gigas hemocyte RB, measured by chemiluminescence with luminol. Preliminary results using wild oysters showed that a concentration of about $1 \times 106$ cells per $\mathrm{ml}$ hemolymph is common. Adding a ratio of 80 particles per hemocytes led to a final 'cells+particles' concentration of $8.1 \times 107$ particles per ml. This concentration is more than four times the optimum cell concentration defined by Becton Dickinson ( $2 \times 107$ cells ml-1) for its cytometer. Moreover, at this concentration, zymosan particles are partially aggregated and co-occur with $C$. gigas hemocytes in the FSC/SSC cytogram. Accordingly, different ratios of zymosan particles to hemocytes were tested $(<80)$ to optimize the DCF assay.

Oysters were bled and pooled as described previously. Each of the three pools was divided into six subsamples of $400 \mu \mathrm{l}$ and distributed into $5 \mathrm{ml}$ polystyrene tubes (Falcon_) maintained on ice. Six conditions were tested: (1) addition to hemolymph of $400 \mu \mathrm{l}$ PMA solution to obtain $10 \mu \mathrm{g}$ ml-1 final concentration, $400 \mu \mathrm{l}$ zymosan to obtain (2) 80, (3) 40, (4) 20 or (5) 10 particles per hemocyte, and (6) $400 \mu \mathrm{l}$ of FSSW for an unactivated control. Eight microliters of the DCFH-DA stock solution $(1 \mathrm{mM})$ was added to each tube to yield a final concentration of $10 \mu \mathrm{M}, 15 \mathrm{~min}$ before adding PMA, zymosan or FSSW. Tubes were incubated at room temperature $\left(20 / 22^{\circ} \mathrm{C}\right)$, and DCF fluorescence was evaluated for each sub-population after 18, 32, 48, 64, 95, 120 and 180 min of incubation. The same experiment was repeated with no DCFH-DA pre-loading time: DCFHDA, zymosan and FSSW were added simultaneously to hemolymph tubes maintained on ice. Then, tubes were maintained at room temperature to be analyzed by cytometry at different incubation times. 


\subsection{AASH effect}

One of the problems with bivalve hemocytes is their capacity to aggregate. To reduce clumping, several authors have used anti-aggregant solution during bleeding to achieve a 50/50 hemolymph/anti-aggregant mixture $[18-20,26]$. In this AASH flow cytometric assay, each of the three pools was divided into eight sub-samples of $150 \mu \mathrm{l}$ and distributed into $5 \mathrm{ml}$ polystyrene tubes (Falcon_) maintained on ice. Sub-samples were diluted $(+150$ $\mu \mathrm{l}$ ) with FSSW (AASH untreated control), or AASH solution to yield 5, 15 or 45\% AASH final concentration. The AASH solution had been previously modified with zymosan particles in half of the sub-samples. Three microliters of the DCFH-DA stock suspension $(1 \mathrm{mM})$ was added to each tube maintained on ice to yield a final concentration of $10 \mu \mathrm{M}$. Tubes then were maintained at $18{ }^{\circ} \mathrm{C}$, and DCF fluorescence for each sub-population was compared (AASH treated or untreated and zymosan activated or not activated) after 30 min incubation.

\subsection{Application: effect of pathogenic vibrios upon oxidative product synthesis}

After hemocyte counting, as described previously, each of the three pools of hemolymph was divided into five sub-samples of $300 \mu \mathrm{l}$ and maintained on ice. Each sub-sample received $300 \mu \mathrm{l}$ of different bacterial suspensions, V. tapetis, Vibrio sp. strain S322, V. splendidus strain sp7 and V. splendidus strain 83, to have 50 cells per hemocyte final concentration, or $300 \mu \mathrm{l}$ of FSSW to be used as a control. Six microliters of the DCFHDA stock suspension $(1 \mathrm{mM})$ was added to each tube to yield a $10 \mu \mathrm{M}$ final concentration. Then, tubes were maintained at incubation temperature (room temperature, $20 / 22{ }^{\circ} \mathrm{C}$ ), and DCF fluorescence was evaluated by flow cytometry after 30, 60,120 and 180 min incubation. Finally, after the measurement at $180 \mathrm{~min}$, zymosan particles ( 40 per hemocyte) were added in each of the five sub-samples to compare the activation capabilities of the hemocytes after $3 \mathrm{~h}$ of contact with vibrios.

\section{Results}

\subsection{CL test}

Instantaneous and cumulative $C L$ activity of non-activated $C$. gigas hemocytes from $t=0$ to $T=155 \mathrm{~min}$ are presented in Fig. 2. The CL activity of hemocytes was very high at $t=0$. CL first decreased strongly, then more slowly to yield stable values. Cumulative data showed a high increase of activity; the values tended to reach a plateau.

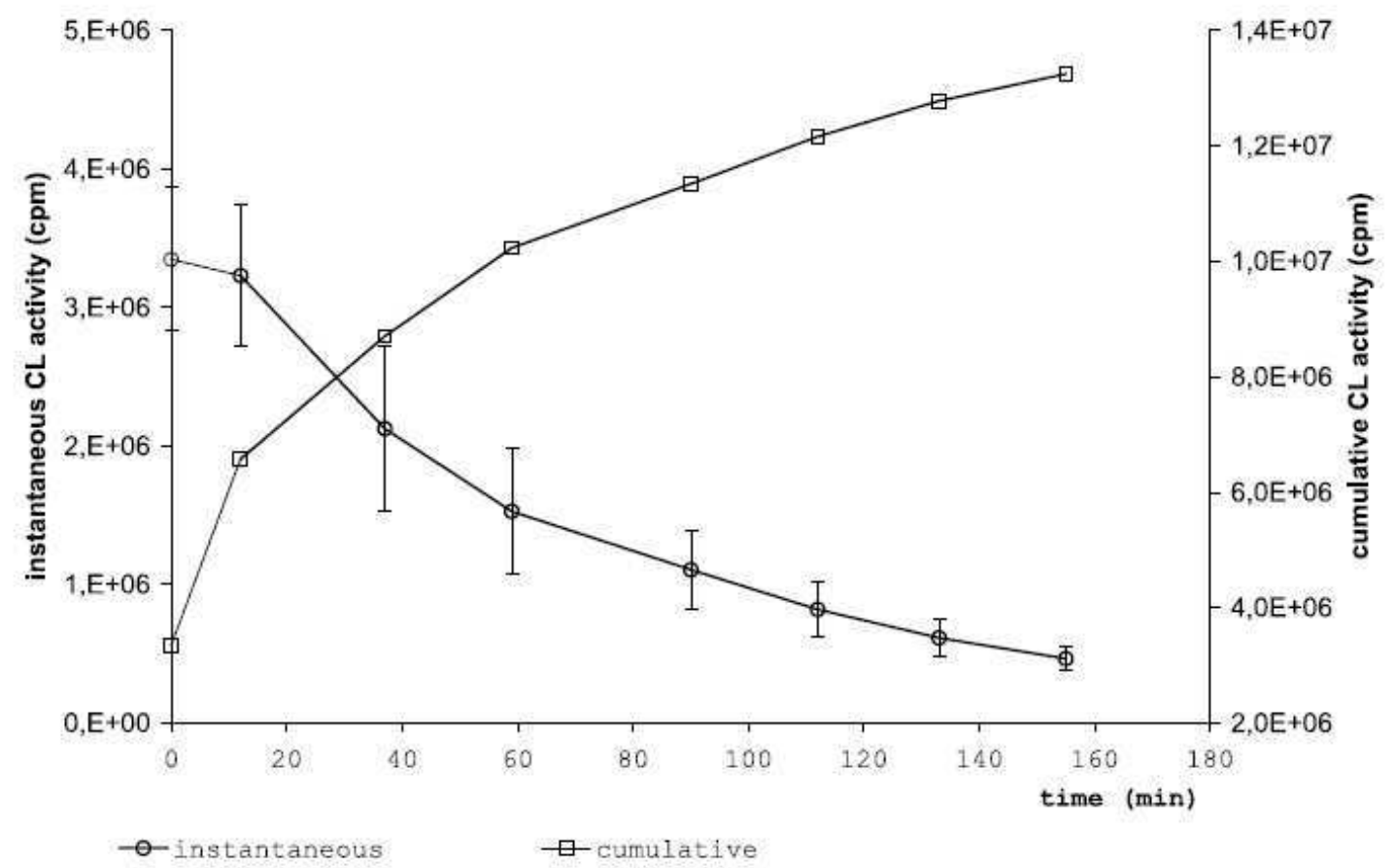

Fig. 2. Instantaneous and cumulative $\mathrm{CL}$ activity in cpm (mean level, $n=3, \pm \mathrm{SE}$ ) of non-activated $\mathrm{C}$. gigas hemocytes $\left(5 \times 10^{4}\right.$ cells in FSSW). 


\subsection{DCFH-DA dose response}

The DCF fluorescence of $C$. gigas hemocytes, with time and according to DCFH-DA loading dose, is presented in Fig. 3a for granulocytes and in Fig. 3b for hyalinocytes. Considering the DCF activity as a cumulative measure of the oxidative metabolism of hemocytes, the DCF activity curves (Fig. 3a, b) and the cumulative CL activity (Fig. 2) can be compared (note that tested hemolymph was not the same). Clearly the same pattern is observed for the $10 \mu \mathrm{M}$ DCFH-DA dose-first a drastic increase then a plateau. For the $100 \mu \mathrm{M}$ DCFH-DA dose, the DCF fluorescence accumulation stopped after $30 \mathrm{~min}$, suggesting that DCFH-DA at this concentration is toxic. For the $0.1 \mu \mathrm{M}$ dose, the fluorescence level of hemocytes was too low to be distinguished from auto-fluorescence of the zymosan particles. The $1 \mu \mathrm{MDCFH}-\mathrm{DA}$ dose seemed to be insufficient to register all the oxidative events in hemocytes, since the $10 \mu \mathrm{M}$ dose led to a higher fluorescence level. As a conclusion, the $10 \mu \mathrm{M}$ DCFH-DA dose appeared to be the optimal concentration. This result was confirmed by looking at the zymosan activation effect on hemocytes loaded with different DCFH-DA doses. A comparison of DCF activity with time of granulocyte activation (+zymosan) or not (+FSSW), depending upon DCFH-DA loading dose, is presented in Fig. 4a, b, c. Statistical analysis (ANOVA, $n=3$ ) showed that there was no significant increase in the DCF fluorescence of zymosan activated granulocytes using 0.1 or $1 \mu \mathrm{M}$ DCFH-DA. However, the $10 \mu \mathrm{M}$ DCFH-DA loading dose revealed a significant increase of the granulocyte DCF fluorescence after zymosan activation.

\section{a: GRANULOCYTES}

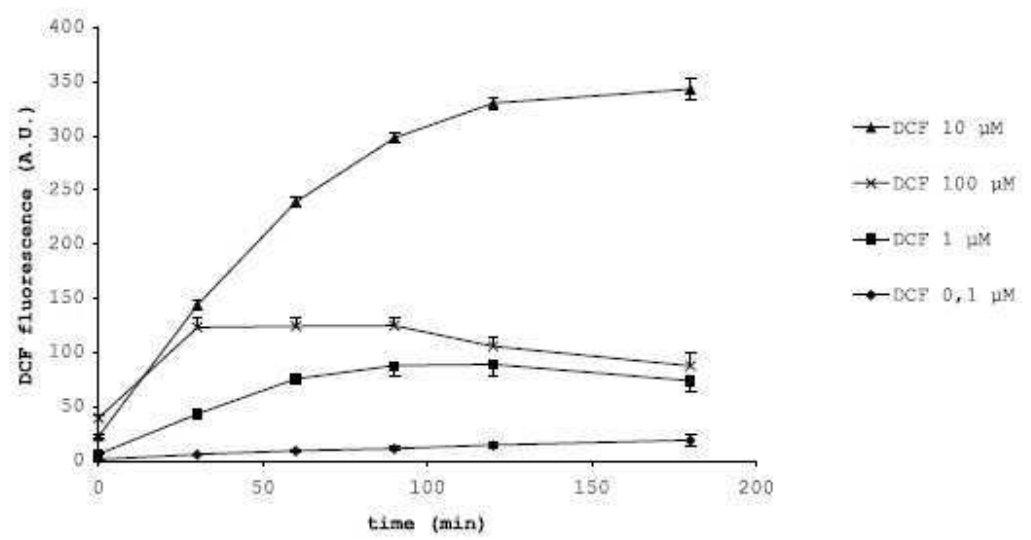

b : HYALINOCYTES

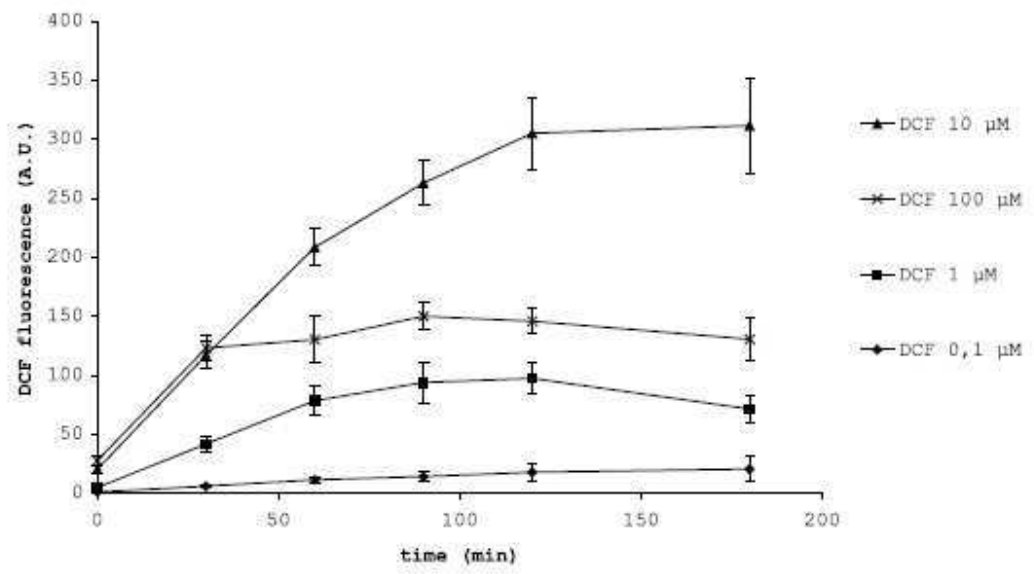

Fig. 3. (a, b) DCF fluorescence level (in arbitrary unit, AU) of non-stimulated ( + FSSW) C gigas hemocytes (mean, $n=3, \pm \mathrm{SD}$ ) from $t=0$ to $t=180 \mathrm{~min}$, depending on the final concentration of the DCFH-DA loading dose: $0.1,1,10$ and $100 \mu \mathrm{M}$. (a) Granulocytes; (b) hyalinocytes. 


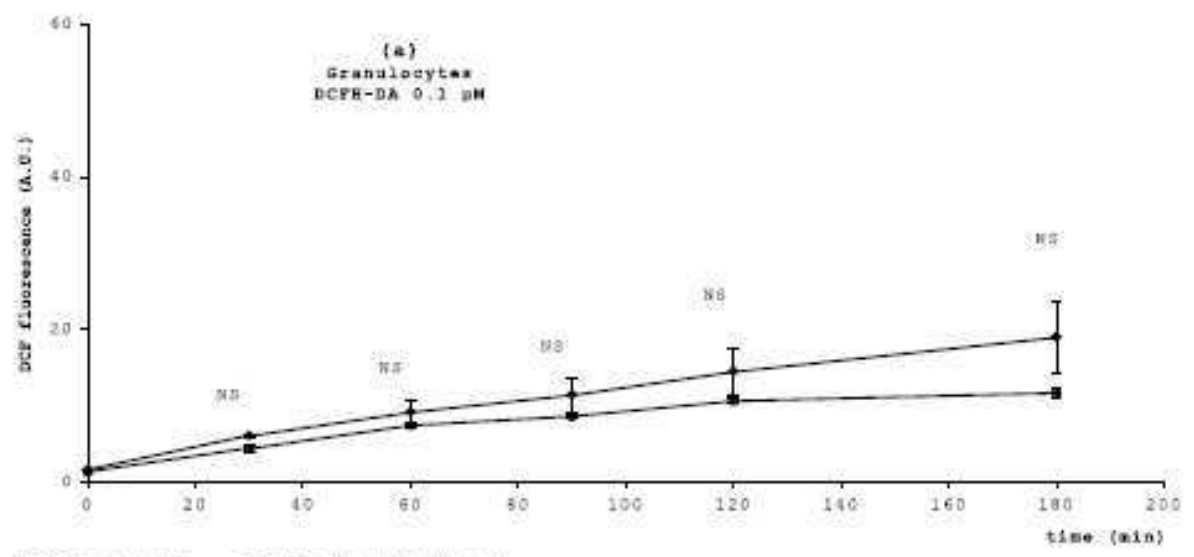

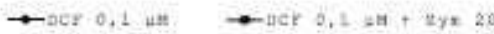

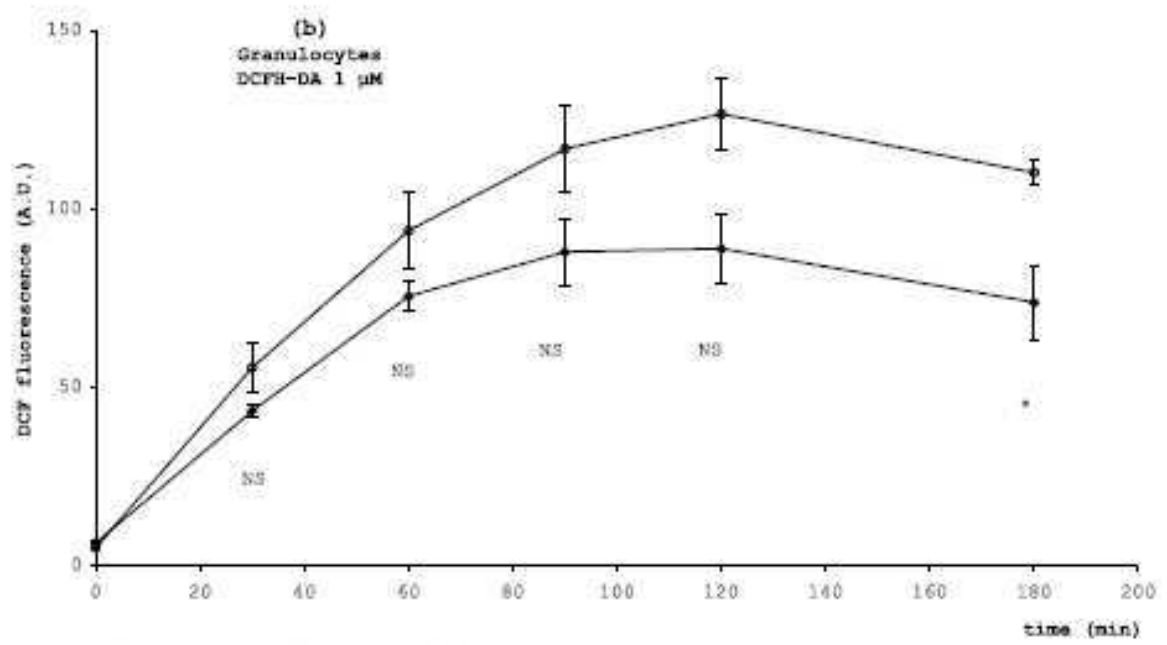

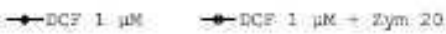

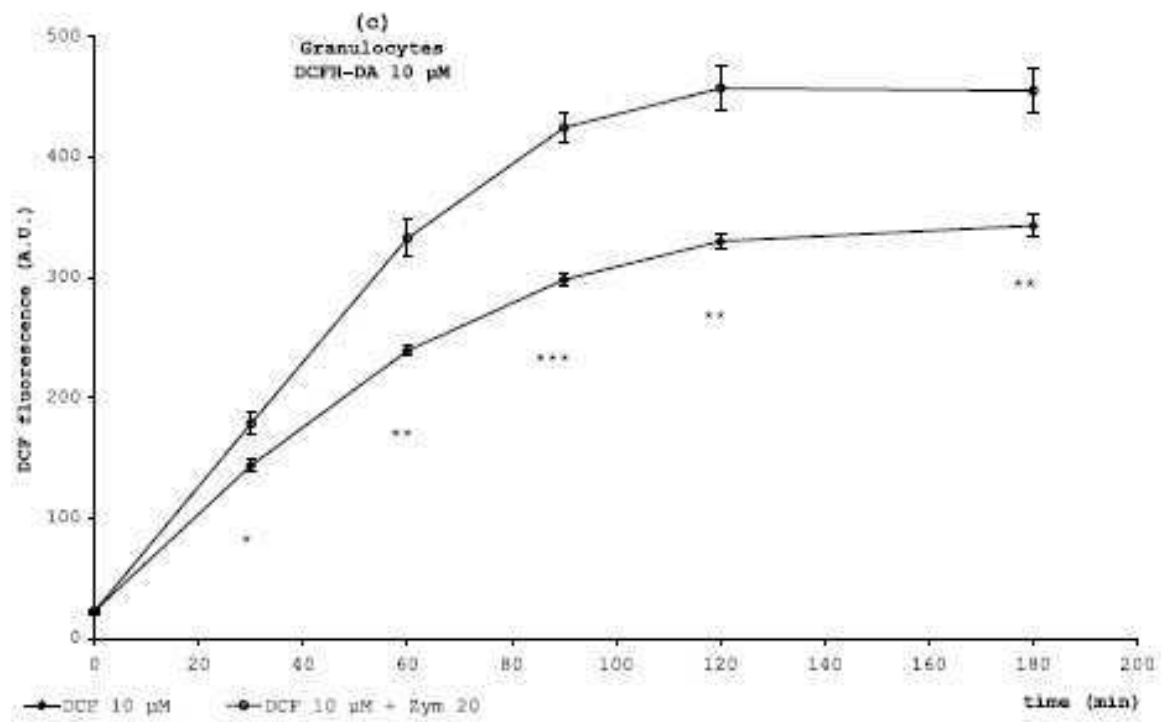

Fig. 4. (a-c) DCF fluorescence level (in arbitrary unit, AU: mean, $n=3, \pm S E$ ) of stimulated ( + zymosan 20 particles per hemocyte) and non-stimulated (+FSSW) $C$, gigas granulocytes, depending on the final concentration of the DCFH-DA loading dose: (a) $0.1 \mu$ M; (b) $1 \mu \mathrm{M}$ and (c) $10 \mu \mathrm{M}$ (mean comparison vs, control, ANOVA; NS, no significant differences; *, significant differences at $p<0.05$; **, $p<0.01 ; * * *, p<0.001)$. 


\subsection{RB activation assay with PMA or zymosan}

\subsubsection{Activation with PMA}

Results of $C$. gigas hemocyte RB activation by PMA, measured as an increase in the DCF fluorescence by flow cytometry, are presented in Table 1. Statistical analysis (ANOVA) showed that there were no statistically significant increases $(n=3, p<0.01)$ of DCF activity level after PMA addition, compared to the control (+FSSW). This result was observed for all hemocyte sub-populations and for all incubation times (18, 32, 46, 64, 95, 120 and $180 \mathrm{~min})$. Moreover, for small agranular cells, DCF activity was lower than the controls at $t=46,64,95$ and $120 \mathrm{~min}$.

\begin{tabular}{|c|c|c|c|c|}
\hline \multirow[t]{2}{*}{ Incubation time (min) } & & \multicolumn{3}{|c|}{ DCF fluorescence (arbitrary unit) } \\
\hline & & Granulocytes & Hyalinocytes & Small agranular cells \\
\hline \multirow[t]{2}{*}{18} & Control & $79 \pm 10$ & $88 \pm 10$ & $24 \pm 4$ \\
\hline & $+\mathrm{PMA}$ & $74 \pm 6$ & $90 \pm 4$ & $19 \pm 1$ \\
\hline \multirow[t]{2}{*}{32} & Control & $121 \pm 11$ & $142 \pm 12$ & $37 \pm 5$ \\
\hline & + PMA & $122 \pm 13$ & $147 \pm 5$ & $26 \pm 2$ \\
\hline \multirow[t]{2}{*}{46} & Control & $161 \pm 12$ & $181 \pm 10$ & $43 \pm 3^{* *}$ \\
\hline & $+\mathrm{PMA}$ & $142 \pm 6$ & $182 \pm 8$ & $31 \pm 2$ \\
\hline \multirow[t]{2}{*}{64} & Control & $201 \pm 9$ & $228 \pm 3$ & $54 \pm 2^{* *}$ \\
\hline & +PMA & $177 \pm 13$ & $212 \pm 8$ & $38 \pm 1$ \\
\hline \multirow[t]{2}{*}{95} & Control & $247 \pm 6$ & $284 \pm 5$ & $73 \pm 2^{* *}$ \\
\hline & + PMA & $227 \pm 18$ & $235 \pm 10$ & $57 \pm 1$ \\
\hline \multirow[t]{2}{*}{120} & Control & $272 \pm 14$ & $307 \pm 20$ & $80 \pm 3 * *$ \\
\hline & $+\mathrm{PMA}$ & $215 \pm 14$ & $226 \pm 12$ & $67 \pm 2$ \\
\hline \multirow{2}{*}{180} & Control & $274 \pm 9$ & $278 \pm 27$ & $74 \pm 5$ \\
\hline & +PMA & $214 \pm 6$ & $189 \pm 9$ & $71 \pm 5$ \\
\hline
\end{tabular}

**, Statistical difference between activated and non-activated cells; ANOVA, $n=3, p<0.01$.

\subsubsection{Activation with zymosan}

Fig. 5 shows the increase of DCF fluorescence with time, depending upon whether granulocytes were activated (+zymosan) or not (+FSSW). Comparison of the DCF mean value of granulocytes activated or not are presented in Table 2 (ANOVA, $n=3, p<0.05$ ). Clearly, there was a DCF-fluorescence increase in activated granulocytes: after $18 \mathrm{~min}$ for doses of 20 and 80; $46 \mathrm{~min}$ for a dose of 40, and $120 \mathrm{~min}$ for a dose of 10. The dose of 20 particles per hemocyte seems to be the best compromise between activation capability and lower particle ratio. This dose allowed a systematic increase of the granulocytes' DCF fluorescence with time, while there is no statistical difference with the maximum dose of 80 particles per hemocyte. Statistical analysis did not show any increase of hyalinocyte DCF activity. In the second experiment, despite a reduction in DCFH-DA loading time, the same results were observed.

Table 2

Comparison of the mean DCF fluorescence values of granulocytes activated (+zymosan) or not $(+\mathrm{FSSW}=$ control)

\begin{tabular}{|c|c|c|c|c|c|c|c|}
\hline Time (min) & 18 & 32 & 46 & 64 & 95 & 120 & 180 \\
\hline Control & a & a & a & a & a & a & a \\
\hline zym 10 & a & $a b$ & $a b$ & $a b$ & $a b$ & b & b \\
\hline zym 20 & b & be & b & be & b & b & b \\
\hline zym 40 & $a b$ & $a b c$ & b & $\mathrm{bc}$ & b & b & b \\
\hline zym 80 & b & $\mathrm{c}$ & b & $\mathrm{c}$ & b & b & b \\
\hline PMA $\left(10 \mu \mathrm{g} \mathrm{ml}^{-1}\right)$ & a & a & a & a & a & a & a \\
\hline
\end{tabular}

Lettering relate the groups to each other and the significant differences between groups. Mean comparison ANOVA, $n=3$, $p<0.05$.

\subsection{Peak of DCF fluorescence}

The incubation time required to achieve the peak of instantaneous DCF fluorescence in C. gigas granulocytes activated by zymosan was evaluated by calculating the polynomial regressions of the curves presented in Fig. 5. For example, the equation for the 'zym 20' curve was: DCF fluo. $=2 \times 106$ (time) $4-0.0006$ (time) $3+0.0498($ time $) 2+1.9348($ time $)+57.367 ; R_{2}=0.9998$.

The first derivative describes the slope of the DCF curve, in other words, the instantaneous variation of the DCF fluorescence. The time of the maximum slope, corresponding to the peak of instantaneous DCF 
fluorescence, was obtained when the second derivative approaches zero. Applying the first and second derivatives to the polynomial regressions obtained with our experimental curves gave the peak of DCF fluorescence after 42, 40, 37 and 42 min incubation, respectively, with 80, 40, 20 and 10 particles of zymosan per hemocyte. To conclude, the peak of instantaneous DCF fluorescence, after activation by zymosan particles, of $C$. gigas hemocytes at $20 / 22^{\circ} \mathrm{C}$ can be estimated as occurring after approximately 40 min of incubation.

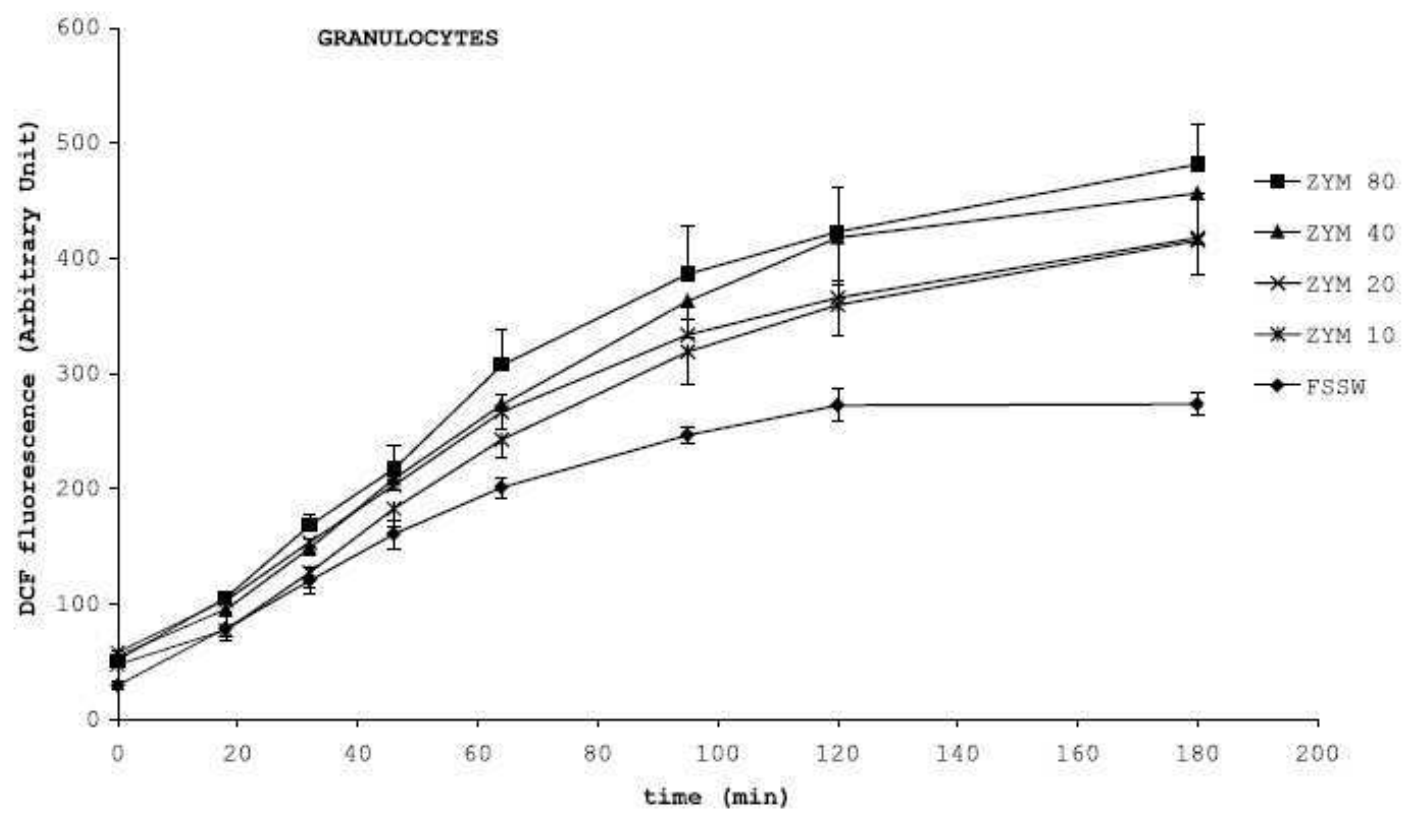

Fig. 5. DCF fluorescence level (in arbitrary unit, AU) of activated (+zymosan) $C$. gigas granulocytes (mean, $n=3, \pm \mathrm{SD}$ ) from $t=0$ to $t=180 \mathrm{~min}$, depending on the zymosan ratio in particles per hemocyte (from 10 to 80 particles per hemocyte).

\subsection{AASH effect}

Results obtained with granulocytes to which AASH was added are shown in Fig. 6 . These results were representative of those obtained for all cell types. Without AASH (control) the DCF fluorescence level increased 2.06 times $30 \mathrm{~min}$ after the addition of zymosan particles. Conversely, no increase (ANOVA, $p<0.05$ ) was measured with a $45 \%$ AASH final concentration. A clear inhibition was noticeable with as little as $5 \%$ AASH.

\subsection{Application: effect of pathogenic vibrios upon oxidative products synthesis}

Results from bacterial addition experiments are presented in Fig. 7 for granulocytes and in Fig. 8 for hyalinocytes. In the first phase, DCF fluorescence increased steadily in control hemocytes. DCF activity was higher in granulocytes (554.6 arbitrary units) compared to hyalinocytes (455.6) after $3 \mathrm{~h}$ of incubation. At $t=180$ min, for both hyalinocytes and granulocytes, the $V$. tapetis strain inhibited DCF oxidation most severely (divided by 1.66 in granulocytes, 1.63 in hyalinocytes). V. splendidus (83) and V. splendidus (sp7) showed the least inhibition for granulocytes. Finally, $1 \mathrm{~h}$ after addition of zymosan ( $t=240 \mathrm{~min}$ ), Vibrio sp. (S322) showed an intermediate response-strong inhibition of granulocytes (equivalent to $V$. tapetis), and hyalinocyte inhibition equivalent to $V$. splendidus (83 and sp7). In summary, the inhibition capacity of bacteria tested for $C$. gigas RB is: V. tapetis > Vibrio $\mathrm{sp} .(\mathrm{S} 322)>V$. splendidus $(83) \geq$. splendidus $(\mathrm{sp} 7)$. 


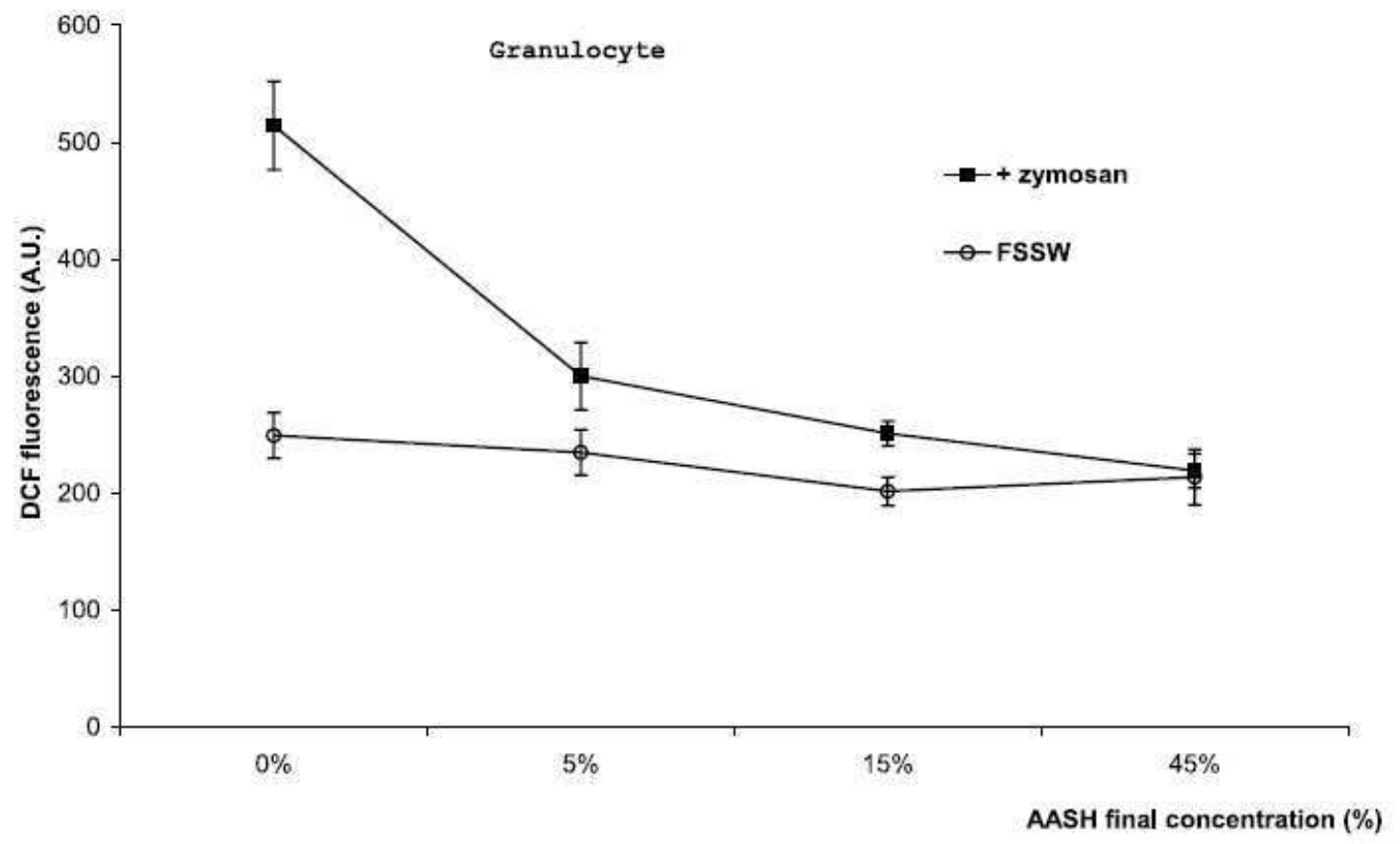

Fig. 6. DCF fluorescence level (in arbitrary unit, AU) of $C$. gigas granulocytes (mean, $n=3, \pm \mathrm{SE}$ ) 30 min after addition of 80 zymosan particles per hemocyte or FSSW depending on whether hemolymph was or not (control) diluted in an anti-aggregant solution (AASH) at 5,15 or $45 \%$ (final concentration).

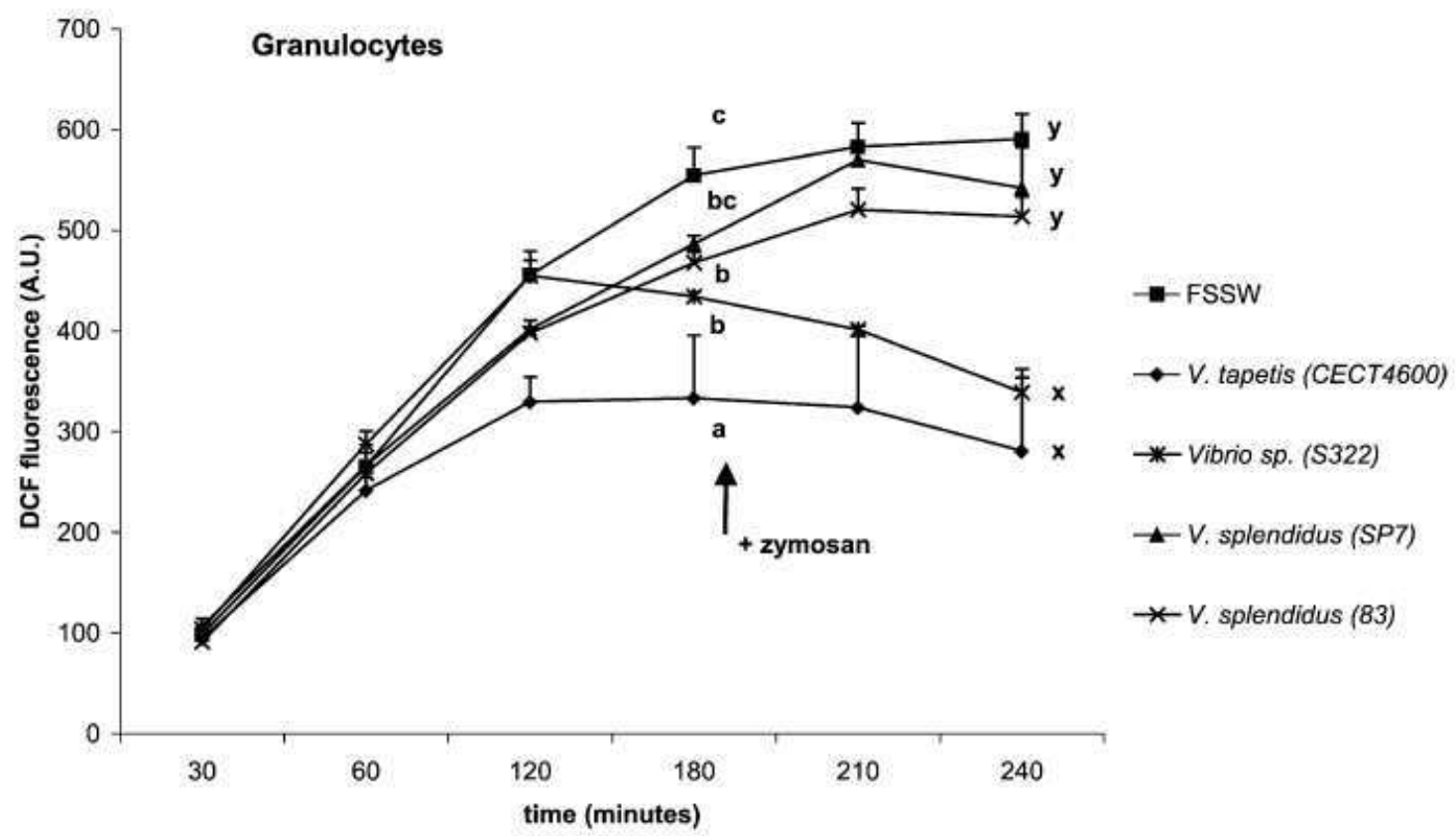

Fig. 7. DCF fluorescence level (in arbitrary unit, AU) of $C$. gigas granulocytes (mean, $n=3, \pm \mathrm{SE}$ ) after addition of different bacterial strains ( 50 cells per hemocyte) or FSSW (control). (1) Addition of 40 particles of zymosan per hemocyte. Lettering indicates significant differences between conditions, ANOVA, $n=3, p<0.05$ (a, b: at $t=180 \mathrm{~min} ; \mathrm{x}, \mathrm{y}:$ at $t=240 \mathrm{~min}$ ). 


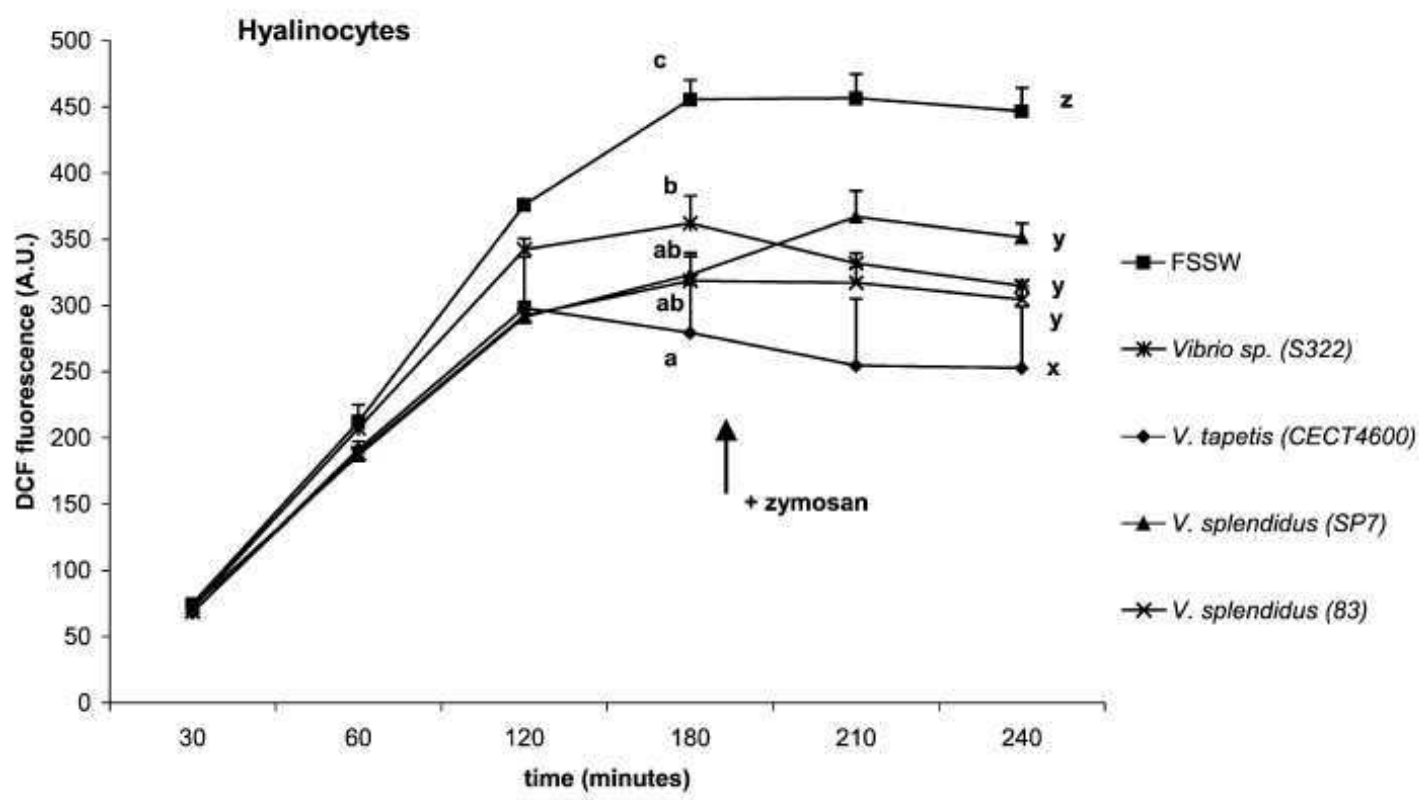

Fig. 8. DCF fluorescence level (in arbitrary unit AU) of $C$. gigas hyalinocytes (mean, $n=3, \pm$ SE) after addition of different bacterial strains ( 50 cells per hemocyte) or FSSW. ( $\uparrow$ ) Addition of 40 particles of zymosan per hemocyte. Lettering indicates significant differences between conditions, ANOVA, $n=3, p<0.05$ (a, b: at $t=180 \mathrm{~min} ; \mathrm{x}$, $\mathrm{y}:$ at $t=240 \mathrm{~min}$ ).

\section{Discussion}

This work demonstrates for the first time the measurement of RB activity in C. gigas hemocytes using a flow cytometric method. The method is based upon intracellular DCFH oxidation to DCF, a highly fluorescent molecule detectable using flow cytometry. Using this method, we showed an activation of RB in C. gigas hemocytes, mainly granulocytes, following phagocytosis of zymosan particles. The peak of activity was estimated to be achieved around 40 min after addition of zymosan. This result can be compared with the 15/20 min observed for $C$. gigas hemocytes using a CL assay [17], 30 min found for $C$. virginica [30], and 45 min for Pecten maximus $[19,20]$. Twenty zymosan particles per hemocyte appeared to be a good compromise for this method and seemed to satisfy the following criteria: a clear increase of the DCF fluorescence with the lowest number of zymosan particles. Moreover, the use of 20 zymosan particles per hemocyte allowed lower standard errors (coefficient variation of $4.2 \%$ ), at least compared with those obtained with 10,40 or 80 particles per hemocyte (coefficient variation of 7.3, 6.3 and $7.9 \%$, respectively). The same differences were obtained in the second zymosan assay, with the addition of zymosan and DCFH-DA simultaneously.

No activation of RB was detected using PMA at $10 \mu \mathrm{g}$ ml-1 final concentration. However, many authors (listed in Ref. [28]) showed an activation of bivalve hemocyte RB by PMA using methods other than flow cytometry (chemiluminescence, formazan/nitro blue tetrazolium assay). This apparent contradiction could be explained by the fact that the hemocytes used during this work were withdrawn without use of any antiaggregant solution and tested without delay after sampling. Hemocytes, therefore, probably were in an excited state, characterized by an increase in DCF fluorescence in control hemocytes over time. This high level of oxidative metabolism was confirmed by the CL assay, where non-activated $C$. gigas hemocytes showed a strong $\mathrm{CL}$ activity at the beginning of the experiment. It is possible that the ROI production was so high without further activation that it was not possible to increase it more with PMA. Zymosan seemed to be a more efficient activator of the RB in this case. This result is consistent with those of previous workers [29,31,32] showing that, unlike vertebrate phagocytes, bivalve hemocytes were less sensitive to PMA than to zymosan particles.

Assay performed without a DCFH-DA loading time showed that this step was not necessary and did not affect the results.

Assays with anti-aggregant solution showed clearly the inhibiting effect of AASH upon the oxidative metabolism. This result is consistent with previous findings [33]. In our protocol, we decided to limit the handling of hemocytes as much as possible, particularly centrifugation used to eliminate anti-aggregant solution. An additional dilution to reduce the anti-aggregant final concentration to $2.5 \%$ as recommended previously [18- 
20,26] was not possible, because this resulted in too low a hemocyte concentration for flow cytometry analysis. Thus, using our protocol, addition of anti-aggregant solution must be avoided.

As an application, the method developed in this work has been used to evaluate the inhibiting effect of different pathogenic bacterial strains upon ROI synthesis during RB in C. gigas hemocytes. Experiments reported here allowed us to classify bacterial strains according to their inhibiting capability. In our study, the two most active strains were described in the literature as pathogenic: V. tapetis to adult $R$. philipinarum [23,24] and Vibrio sp. strain S322 to C. gigas and P. maximus larvae [25]. It was surprising that a strain pathogenic to clams was the most active strain against $C$. gigas hemocytes. Moreover, experimental infection in $C$. gigas palleal cavity with $V$. tapetis did not lead to any disease symptom or mortality [34]. This suggests prudence in evaluating pathogenic-strain virulence using such a method. Our in vitro challenge did not take into account all the possible virulence factors, particularly those linked to non-hemocyte, 'humoral' defenses of the host.

The use of a strain with moderate inhibiting capability, such as the $C$. gigas larvae pathogenic Vibrio sp. S322, can be considered as a possible experimental tool. Testing this strain on different oysters may be used to estimate the resistance capacity of these animals to a pathogen. Complementary work must be done to describe in detail the specific steps in DCF formation during the RB pathway, particularly by using specific inhibitors, so that we may better understand the inhibiting activity of pathogenic bacteria upon oyster hemocytes.

\section{Acknowledgements}

This work was partially supported by grants from the Laboratory of Invertebrate Physiology, IFREMER, Brest, France (contract IFREMER/ LEMAR, IF 01.2.521.409). We thank the Argenton hatchery (IFREMER, Finiste`re, France) for supplying oysters, the Laboratory of Genetics and Pathology (IFREMER, La Tremblade, France) for supplying V. splendidus sp7 (or TENMF6), Jean-Louis Nicolas from the Laboratory of Marine Invertebrate Physiology (IFREMER, Brest, France) for supplying Vibrio sp. strain S322 and V. splendidus II strain 83, and Gary Wikfors for critical reading of the manuscript.

\section{References}

[1] Thompson RF. Blood chemistry, biochemical composition, and the annual reproductive cycle in the giant scallop, Placopecten magellanicus, from southeast Newfoundland. J Fish Res Board Can 1977;34:2104-16.

[2] Fisher WS, Ford SE. Flow cytometry: a tool for cell research in bivalve pathology. Am Fish Soc Spec Publ 1977;18:286-91.

[3] Friedl FE, Alvarez MR, Johnson JS, Gratzner HG. Cytometric investigations on hemocytes of the American oyster, Crassostrea virginica. Tissue Cell 1988;20:933-9.

[4] Alvarez MR, Friedl FE, Johnson JS, Hinsch GW. Factors affecting in vitro phagocytosis in oyster hemocytes. J Invertebr Pathol 1989;54:233-41.

[5] Ottaviani E. Haemocytes of the freshwater snail Viviparus ater (Gastropoda, Prosobranchia). J Molluscan Stud 1989;55:379-82.

[6] Ford SE, Ashton-Alcox KA, Kanaley SA. Comparative cytometric and microscopic analyses of oyster hemocytes. J Invertebr Pathol 1994;4:114-22.

[7] Barcia R, Cao A, Arbeteta J, Ramos-Martinez JI. The IL-2 receptor in hemocytes of the sea mussel Mytilus galloprovincialis Lmk. IUBMB Life 1999;48:419-23.

[8] Renault T, Xue QG, Chilmonczyk S. Flow cytometric analysis of European flat oyster, Ostrea edulis, haemocytes using a monoclonal antibody specific for granulocytes. Fish Shellfish Immunol 2001;11:269-74.

[9] Moore JD, Elston RA, Drum AS, Wilkinson MT. Alternate pathogenesis of systemic neoplasia in the bivalve mollusc Mytilus. J Invertebr Pathol 1991;58:231-43.

[10] White MK, Miosky D, Flessas DA, Reinisch CL. The expression of an adhesion-related protein by clam hemocytes. J Invertebr Pathol 1993;61:253-9.

[11] Barardi CR, Yip H, Emsile KR, Vesey G, Shanker SR, Williams KL. Flow cytometry and RT-PCR for rotavirus detection in artificially seeded oyster meat. Int J Food Microbiol 1999;49:9-18.

[12] Fournier M, Pellerin J, Clermont Y, Morin Y, Brousseau P. Effects of in vivo exposure of Mya arenaria to organic and inorganic mercury on phagocytic activity of hemocytes. Toxicology 2001;161:201-11.

[13] Bass DA, Parce JW, Dechatelet LR, Szejda P, Seeds MC, Thomas M. Flow cytometric studies of oxidative product formation by neutrophils: a graded response to membrane stimulation. J Immunol 1983;130:1910-7.

[14] Rothe G, Valet G. Flow cytometric analysis of respiratory burst activity in phagocytes with hydroethidine and 2',7'-dichlorofluorescin. J Leukoc Biol 1990;47:440-8.

[15] Heinzelmann M, Herzig DO, Swain B, Mercer-Jones MA, Bergamini TM, Polk HC Jr.. Phagocytosis and oxidative-burst response of planktonic Staphylococcus epidermidis RP62A and its non-slime-producing variant in human neutrophils. Clin Diagn Lab Immunol 1997:4:705-10. 
[16] Van-Eeden SF, Klut ME, Walker BAM, Hogg JC. The use of flow cytometry to measure neutrophil function. J Immunol Methods 1999;232:23-43 Special issue SI.

[17] Torreilles J, Guerin MC, Roch P. Reactive oxygen species and defense mechanisms in marine bivalves. C R Acad Sci Ser III 1996; 319:209-18 in French.

[18] Bache`re E, Hervio D, Mialhe E. Luminol-dependent chemiluminescence by hemocytes of two marine bivalves, Ostrea edulis and Crassostrea gigas. Dis Aquat Org 1991;11:173-80.

[19] Le Gall G, Bache`re E, Mialhe E. Chemiluminescence analysis of the activity of Pecten maximus hemocytes stimulated with zymosan and host-specific rickettsiales-like organisms. Dis Aquat Org 1991;11:181-6.

[20] Lambert C, Nicolas JL. Specific inhibition of chemiluminescent activity by pathogenic vibrios in hemocytes of two marine bivalves, Pecten maximus and Crassostrea gigas. J Invertebr Pathol 1998;71:53-63.

[21] Auffret M, Oubella R. Cytological and cytometric analysis of bivalve mollusc hemocytes. In: Stolen JS, Fletcher TC, Smith SA, Zelikoff JT, Kaattari SL, Anderson RS, So “derha 11 K, Weeks-Perkins BA, editors. Techniques in fish immunology. Fair Haven: SOS Publications; 1995, pp. 55-64.

[22] Borrego JJ, Castro D, Luque A, Paillard C, Maes P, Garcia MT et al. Vibrio tapetis sp. nov., the causative agent of the brown ring disease affecting cultured clams. Int J Syst Bacteriol 1996;46:480-4.

[23] Paillard C, Maes P. The brown ring disease in the Manila clam, Ruditapes philippinarum. 1: Ultrastructural alterations of the periostracal lamina. J Invertebr Pathol 1995;65:91-100.

[24] Paillard C, Maes P. The brown ring disease in the Manila clam, Ruditapes philippinarum. 2: Microscopic study of the brown ring syndrome. J Invertebr Pathol 1995;65:101-10.

[25] Nicolas J-L, Corre S, Gauthier G, Robert R, Ansquer D. Bacterial problems associated with scallop (Pecten maximus) larval culture. Dis Aquat Org 1996;27:67-76.

[26] Lambert C, Nicolas J-L, Bultel V. Toxicity to Pecten maximus hemocytes of Vibrio pectenicida extract. J Invertebr Pathol 2001; 77:165-72.

[27] Waechter M, Le Roux F, Nicolas J-L, Marissal E, Berthe F. Caractérisation de bactéries pathogènes de naissains d'huître creuse Crassostrea gigas. C R Biol 2002;325:1-8 in French.

[28] Arumugam M, Romestand B, Torreilles J, Roch P. In vitro production of superoxide and nitric oxide (as nitrite and nitrate) by Mytilus galloprovincialis haemocytes upon incubation with PMA or laminarin or during yeast phagocytosis. Eur J Cell Biol 2000; 79:513-9.

[29] Ordas MC, Novoa B, Figueras A. Modulation of the chemiluminescence response of Mediterranean mussel (Mytilus galloprovincialis) haemocytes. Fish Shellfish Immunol 2000;10:611-22.

[30] Larson KG, Robertson BS, Hetrick FM. Effect of environmental pollutants on the chemiluminescence of hemocytes of the American oyster Crassostrea virginica. Dis Aquat Org 1989;6:131-6.

[31] Austin KA, Paynter KT. Characterization of chemiluminescence measured in haemocytes of the Eastern oyster, Crassostrea virginica. J Exp Zool 1995;273:461-73.

[32] Torreilles J, Guerin MC, Roch P. Peroxidase-release associated with phagocytosis in Mytilus galloprovincialis haemocytes. Dev Comp Immunol 1997;21:267-75.

[33] Torreilles J, Guerin MC, Roch P. Modified Alsever's solution is not a good medium for reactive oxygen metabolite study in bivalves. Fish Shellfish Immunol 1999;8:65-9.

[34] Maes P, Paillard C. Effet de Vibrio P1, pathoge`ne de Ruditapes philippinarum sur d'autres espe`ces de bivalves. Haliotis 1992; 14:1418 in French. 